\title{
Lesões das estruturas do joelho em jogadores de futebol
}

\author{
Injuries to the knee structures in soccer \\ Lesiones en las estructuras de la rodilla en jugadores de fútbol
}

\author{
José Trajano Feitoza Neto \\ ORCID: https://orcid.org/0000-0001-6281-0955 \\ Instituto Tocantinense Presidente Antônio Carlos, Brasil \\ E-mail: netofeitoza123@gmail.com \\ Gabriel Costa Simiema \\ ORCID: https://orcid.org/0000-0003-3916-817X \\ Instituto Tocantinense Presidente Antônio Carlos, Brasil \\ E-mail: gabrielcosta35@hotmail.com \\ Thiago Henrique da Silva Souza \\ ORCID: https://orcid.org/0000-0003-0605-0191 \\ Instituto Tocantinense Presidente Antônio Carlos, Brasil \\ E-mail: thiago_henrique_21@hotmail.com \\ Vinicius Borges da Costa \\ ORCID: https://orcid.org/0000-0003-1294-8264 \\ Instituto Tocantinense Presidente Antônio Carlos, Brasil \\ E-mail: viniciusborgesdacosta@hotmail.com \\ Isnaya Almeida Brandão Lima \\ ORCID: https://orcid.org/0000-0002-5725-7195 \\ Instituto Tocantinense Presidente Antônio Carlos, Brasil \\ E-mail: nayabrandao@gmail.com
}

\begin{abstract}
Resumo
Os índices de lesões de joelho em jogadores de futebol são extremamente elevados quando comparados a outros tipos de lesões ou a outros grupos de atletas. Tal realidade pode ser atribuída à maior exposição ao choque dessa articulação ou à elevada carga de treino a que esses atletas são constantemente submetidos. O objetivo deste trabalho foi, através de uma Revisão Integrativa da literatura a partir das bases de dados da Biblioteca Virtual em Saúde (BVS): Scielo, Lilacs, Periódicos Capes e Pubmed, conhecer esses índices, identificar quais as estruturas mais afetadas e observar se existe relação entre a ocorrência da lesão e a posição em que o jogador atua. Foi encontrado um número expressivo de artigos que mostraram, entre outras coisas, que os zagueiros e atacantes são os grupos mais propensos a se lesionarem pela alta quantidade de saltos realizados durante as partidas, deixando evidente a necessidade de aperfeiçoar esses e outros movimentos. Ainda assim, percebemos a necessidade de novos estudos que identifiquem melhor os fatores envolvidos nas lesões de joelho e descrevam as melhores estratégicas de prevenção dessas injúrias que impactam negativamente nas carreiras desses atletas.
\end{abstract}

Palavras-chave: Ferimentos e lesões; Ligamentos; Menisco; Articulação do joelho; Futebol.

\begin{abstract}
Knee injury rates in soccer players are extremely high when compared to other types of injuries or other groups of athletes. This reality can be attributed to the greater exposure to shock in this joint or the high training load to which these athletes are constantly submitted. The objective of this work was, through an Integrative Literature Review from the Virtual Health Library (VHL) databases: Scielo, Lilacs, Capes Periodicals and Pubmed, to know these indexes, identify which structures are most affected and observe if there is a relationship between the occurrence of the injury and the position in which the player acts. A significant number of articles were found that showed, among other things, that defenders and strikers are the groups most likely to be injured due to the high number of jumps performed during matches, making evident the need to improve these and other movements. Still, we realize the need for new studies that better identify the factors involved in knee injuries and describe the best strategies for preventing these injuries that negatively impact the careers of these athletes.
\end{abstract}

Keywords: Wounds and injuries; Ligaments; Meniscus; Knee joint; Soccer.

\section{Resumen}

Las tasas de lesiones de rodilla en jugadores de fútbol son extremadamente altas en comparación con otros tipos de lesiones u otros grupos de atletas. Esta realidad se puede atribuir a la mayor exposición al choque en esta articulación o la alta carga de entrenamiento a la que están constantemente sometidos estos deportistas. El objetivo de este trabajo fue, a través de una Revisión Integrativa de Literatura de las bases de datos de la Biblioteca Virtual en Salud (BVS): 
Scielo, Lilacs, Capes Periodicals y Pubmed, conocer estos índices, identificar qué estructuras son las más afectadas y observar si existe una relación entre la ocurrencia de la lesión y la posición en la que actúa el jugador. Se encontró un importante número de artículos que mostraban, entre otras cosas, que los defensas y delanteros son los grupos con mayor probabilidad de lesionarse debido al elevado número de saltos realizados durante los partidos, evidenciando la necesidad de mejorar estos y otros movimientos. Aún así, nos damos cuenta de la necesidad de nuevos estudios que identifiquen mejor los factores involucrados en las lesiones de rodilla y describan las mejores estrategias para prevenir estas lesiones que impactan negativamente en la carrera de estos atletas.

Palabras clave: Heridas y lesiones; Ligamentos; Menisco; Articulación de la rodilla; Fútbol.

\section{Introdução}

No Brasil, nação mundialmente conhecida como "o país do futebol", há muitos jovens e crianças que veem seu futuro neste esporte. No entanto, muitas carreiras têm acabado antes mesmo de começar por conta de lesões de joelho. As possíveis causas vão desde o estresse mecânico até as causas genéticas. Dentre as lesões de joelho, as que afetam o ligamento cruzado anterior associado ao menisco são as de maior incidência, o que reforça a teoria de que as lesões ligamentares em seres humanos são muito comuns. Os atletas que atuam no meio de campo e no ataque, por serem os mais requisitados fisicamente durante as partidas, são os mais acometidos.

Acredita-se que os jogadores sofrem com esses tipos de lesões devido ao excesso de jogos durante o ano, o que acumula cansaço, sobrecarga muscular e pouco tempo para recuperação. Uma alternativa seria a redução de jogos durante o ano ou ainda o fortalecimento dos principais ligamentos acometidos: ligamento cruzado anterior, ligamento colateral-tibial e menisco. Outra possível solução seria o investimento nas fases de recuperação física, resultando em melhor desempenho e menor ocorrência médica.

O futebol, como esporte mais difundido e praticado no nosso país, precisa ser entendido como ambiente propício para a ocorrência das lesões de joelho.

Existem diversos tipos de lesões no joelho e a maioria delas demandam um tempo considerável de recuperação. Então, é de extrema importância realizar estudos sobre as principais lesões do joelho para uma melhor eficácia dos tratamentos.

Diante disso, fica evidente a relevância e atualidade do tema que pode ser considerado como um problema de saúde pública, visto que tem alta incidência em pessoas que praticam o referido esporte. A ocorrência dessas lesões traz sobrecarga ao sistema público de saúde, principalmente nos setores de ortopedia e fisioterapia, já saturados.

Assim, conhecer a epidemiologia das lesões de joelho no âmbito do futebol se faz necessário para entendermos como as atividades esportivas podem causá-las e, desta forma, propor medidas de promoção e prevenção mais efetivas. Além disso, propiciar a melhoria da qualidade de vida dos atletas profissionais e amadores de futebol.

Dessa forma, esse trabalho visa enfatizar a quantidade e as características das lesões do joelho desse grupo de atletas de forma a facilitar a definição de formas e medidas preventivas durante os treinos e partidas, e assim reduzir a incidência de lesões no ambiente futebolístico.

O presente estudo tem como objetivo, conhecer o grau de acometimento desses atletas por lesões de joelho, quais as estruturas mais afetadas e qual a relação entre o tipo de lesão e a posição em que o jogador atua dentro de campo, de modo a responder à seguinte pergunta de pesquisa: Quais as principiais lesões de joelho e qual a sua dinâmica em jogadores de futebol?

\section{Metodologia}

Trata-se de uma revisão integrativa de literatura com resultados através de pesquisas realizadas nas bases de dados da Biblioteca Virtual em Saúde (BVS): Scielo, Lilacs, Periódicos Capes e Pubmed. Foram selecionados artigos publicados no 
período de 2010-2021. Após a seleção do material, foi realizada uma leitura exploratória das obras bibliográficas com o objetivo de verificar quais os conteúdos dos artigos consultados tinham relação com a pesquisa. Em seguida, foi proferida a leitura analítica dos artigos, com a finalidade de ordenar e sumarizar os dados contidos nas fontes, buscando - se a obtenção de respostas ao problema da pesquisa.

Foram incluídos artigos gratuitos disponíveis para download, escritos na língua portuguesa brasileira, preferencialmente revisões de literatura com temáticas relacionadas a anatomia e as estruturas do joelho mais lesionadas em jogadores de futebol, publicados entre os anos de 2010 e 2021.

Os fatores de exclusão foram: artigos publicados antes de 2010 que não abordavam as principais lesões no joelho, especificamente em jogadores de futebol; artigos que não estavam disponíveis de forma gratuita; e aqueles que fugiram do tema proposto.

Após uma busca inicial na base de dados citados anteriormente foram encontrados aproximadamente 100 artigos. Foram aplicados critérios de exclusão e inclusão, restando 32 (trinta e dois) trabalhos, cujos resumos foram analisados. A partir deste filtro, foram selecionados 21 (vinte e um) artigos a serem lidos na íntegra. Ao final deste percurso metodológico, selecionamos 10 artigos para o trabalho final, por responderem à nossa pergunta de pesquisa.

\section{Resultados}

Dos 10 artigos analisados nesta revisão integrativa, observou-se que quatro (40\%) são do período de 2011 a 2015; enquanto seis (60\%) são de 2016 a 2021. Em relação ao tipo de estudo, percebeu-se uma predominância (80\%) nas análises observacionais e prospectivas. No quadro a seguir pode-se observar os trabalhos estudados e selecionados para este estudo, sendo apresentado a base de dados, autores, periódicos, ano de publicação, tipos de estudo, além dos resultados e conclusões das pesquisas. 
Quadro 1 - Principais dados dos estudos analisados (2011 a 2021).

\begin{tabular}{|c|c|c|c|c|}
\hline $\begin{array}{l}\text { AUTOR/ ANO/ } \\
\text { PERIÓDICO }\end{array}$ & AMOSTRA/LOCAL & $\begin{array}{l}\text { TIPO DE } \\
\text { ESTUDO }\end{array}$ & PRINCIPAIS RESULTADOS & CONCLUSÕES \\
\hline $\begin{array}{l}\text { Zabka, et al. } 2011 . \\
\text { Revista Brasileira } \\
\text { de Medicina do } \\
\text { Esporte }\end{array}$ & $\begin{array}{l}\text { A amostra consistiu de } 39 \text { atletas } \\
\text { pertencentes a um clube de futebol } \\
\text { de elite da capital gaúcha. }\end{array}$ & $\begin{array}{c}\text { Estudo } \\
\text { observacional }\end{array}$ & $\begin{array}{l}\text { Os valores obtidos analisam atletas em movimento sem } \\
\text { alteração de velocidade, comparando os membros inferiores. } \\
\text { Foi observado um desequilíbrio muscular em relação aos } \\
\text { músculos extensores e flexores do joelho. Possibilitando dessa } \\
\text { forma valores de referência para treino em atletas de futebol, } \\
\text { para reduzir os números de lesões evitáveis. }\end{array}$ & $\begin{array}{l}\text { As lesões musculares são responsáveis por várias } \\
\text { enfermidades no futebol. Sendo assim é de suma } \\
\text { importância uma análise individual da condição } \\
\text { muscular de cada atleta, resultando em treinos } \\
\text { planejados e específicos. Diminuindo ou até } \\
\text { extinguindo as deficiências musculares. }\end{array}$ \\
\hline $\begin{array}{l}\text { Carvalhais et al., } \\
\qquad 2013 . \\
\text { Revista Brasileira } \\
\text { Medicina do } \\
\text { Esporte }\end{array}$ & $\begin{array}{l}164 \text { atletas profissionais de futebol } \\
\text { avaliados no período de pré- } \\
\text { temporada entre os anos de } 2008 \text { e } \\
\text { 2011. A amostra foi constituída de } \\
40 \text { atacantes, } 27 \text { zagueiros, } 23 \\
\text { laterais, } 61 \text { meio-campistas e } 13 \\
\text { goleiros, em Belo Horizonte, MG, } \\
\text { Brasil. }\end{array}$ & $\begin{array}{l}\text { Estudo } \\
\text { retrospectivo }\end{array}$ & $\begin{array}{l}\text { Não houve diferença significativa na assimetria de pico de } \\
\text { toque (PT), de trabalho máximo (T) e índice de fadiga (IF) } \\
\text { isocinética dos extensores e flexores do joelho entre os cinco } \\
\text { posicionamentos em campo, apenas o índice de fadiga dos } \\
\text { flexores é superior ao dos extensores no membro inferior } \\
\text { dominante e não dominante. }\end{array}$ & $\begin{array}{l}\text { Diante da amostra realizada nesse estudo, a posição } \\
\text { de jogador não influencia diretamente a capacidade } \\
\text { de geração de força dos flexores e extensores do } \\
\text { joelho, e a ocorrência de lesões não tem ligação de } \\
\text { acordo com a posição em campo do atleta. O índice } \\
\text { de fadiga dos flexores é maior que dos extensores } \\
\text { do joelho. }\end{array}$ \\
\hline $\begin{array}{l}\text { Revista Brasileira } \\
\text { de Ciência e } \\
\text { Movimento }\end{array}$ & $\begin{array}{l}\text { A amostra foi composta por } \\
\text { jogadores de futebol profissional } \\
(\mathrm{N}=24) \text { do gênero masculino com } \\
\text { idade mínima de } 18 \text { anos, em } \\
\text { treinamento regular, aptos a } \\
\text { realizarem exercícios físicos, sem } \\
\text { história prévia de cirurgia na } \\
\text { articulação do joelho, e que não } \\
\text { sofreram lesão nos últimos } 6 \text { meses. }\end{array}$ & $\begin{array}{l}\text { Estudo } \\
\text { observacional, } \\
\text { analítico do tipo } \\
\text { transversal }\end{array}$ & $\begin{array}{l}\text { A análise do grupo de atletas profissionais foi composta por } \\
24 \text { jogadores, sendo } 12 \text { de defesa, } 8 \text { de meio-campo e } 4 \\
\text { atacantes. Atendendo a análise da musculatura flexora do } \\
\text { joelho, podemos verificar que houve diferença } \\
\text { estatisticamente significativa no pico de torque entre membro } \\
\text { dominante e não dominante nos atletas de meio campo. A } \\
\text { análise da musculatura extensora do joelho revela que houve } \\
\text { diferença estatisticamente significativa em relação a membro } \\
\text { dominante e não dominante, somente nos atletas da defesa, em } \\
\text { ambas as velocidades angulares. }\end{array}$ & $\begin{array}{l}\text { Os atletas, pelo desempenho isocinético, priorizam } \\
\text { o seu lado dominante durante os treinamentos e } \\
\text { jogos, quando comparado com o lado não } \\
\text { dominante. Além disso os jogadores apresentaram } \\
\text { diminuição da força muscular tanto nos músculos } \\
\text { extensores quanto flexores, mesmo estes estando no } \\
\text { decorrer da temporada. }\end{array}$ \\
\hline $\begin{array}{l}\text { Waldén at al., } \\
2015 .\end{array}$ & $\begin{array}{l}\text { Cinco analistas avaliaram vídeos de } \\
39 \text { rupturas completas do LCA } \\
\text { gravadas por meio de vigilância de } \\
\text { lesões em jogadores profissionais de } \\
\text { futebol entre } 2001 \text { e } 2011 \text {. }\end{array}$ & $\begin{array}{c}\text { Estudos } \\
\text { prospectivos }\end{array}$ & $\begin{array}{l}\text { Das } 39 \text { lesões LCA avaliadas, } 25 \text { foram sem contato, } 8 \text { com } \\
\text { contato indireto e } 6 \text { com contato direto, as principais causas } \\
\text { foram: (1) por pressão, (2) recuperar o equilíbrio pós chutar, } \\
\text { (3) aterrissar após cabecear, (4) contato direto com a perna ou } \\
\text { joelho lesionado. Os jogadores defensivos tiveram o maior } \\
\text { número de lesões, } 20 \text { jogadores estavam sem a bola no } \\
\text { momento da lesão. }\end{array}$ & $\begin{array}{l}\text { É necessário intervir nas principais causas das } \\
\text { lesões, principalmente em jogadores defensivos, } \\
\text { técnicas como salto e aterrissagem durante a } \\
\text { disputa do cabeceio, manter o equilíbrio durante o } \\
\text { chute são importantes para a redução dessas lesões. }\end{array}$ \\
\hline
\end{tabular}




\begin{tabular}{|c|c|c|c|c|}
\hline $\begin{array}{c}\text { Revista Brasileira } \\
\text { de Ortopedia }\end{array}$ & $\begin{array}{l}240 \text { pacientes com lesão do } \\
\text { ligamento cruzado anterior e /ou } \\
\text { meniscal, submetidos a tratamento } \\
\text { cirúrgico, de diferentes modalidades } \\
\text { esportivas no Brasil. }\end{array}$ & $\begin{array}{c}\text { Estudo } \\
\text { observacional } \\
\text { prospectivo }\end{array}$ & $\begin{array}{l}\text { Dos } 240 \text { pacientes, } 44,58 \% \text { apresentaram lesão isolada do } \\
\text { LCA, 30,2\% lesão do LCA associada à lesão meniscal e } 25 \% \\
\text { lesão de menisco isolada. As taxas de incidência dessas lesões } \\
\text { em jogadores de futebol foi respectivamente: } 53,27 \%, 50,69 \% \\
\text { e } 61,67 \% \text {. No sexo masculino essas taxas subiram para } \\
87,72 \%, 83,79 \% \text { e } 94,59 \% \text {. O tempo de prática do futebol } \\
\text { para esses grupos de lesões ficaram respectivamente } 17 ; 20,11 \\
\text { e } 25,59 \text {. Ainda em relação ao tempo de prática, a incidência de } \\
\text { LCA ficou d } 0,523 / 1000 \mathrm{~h}(0,507 / 1000 \mathrm{~h} \text { para homens e } \\
0,871 / 1000 \mathrm{~h} \text { para mulheres) e para lesões meniscais } \\
0,448 / 1000 \mathrm{~h}(0,435 / 1000 \mathrm{~h} \text { para homens e } 0,596 / 1000 \mathrm{~h} \text { para } \\
\text { mulheres). }\end{array}$ & $\begin{array}{l}\text { De todas as modalidades esportivas o futebol foi o } \\
\text { esporte que mais provocou lesões do LCA, dos } \\
\text { meniscos e lesões do LCA associadas a meniscais. } \\
\text { Observa-se também que dos três tipos de lesões a } \\
\text { que levou menos tempo de prática para acontecer } \\
\text { foi a do LCA, seguido da lesão meniscal isolada. } \\
\text { Conclui - se também que os homens tem menos } \\
\text { chances de adquirir lesões meniscais e de LCA em } \\
1000 \text { horas de jogo/treino. }\end{array}$ \\
\hline $\begin{array}{l}\text { Onaka et al., } \\
2017 . \\
\\
\text { Revista } \\
\text { Fisioterapia em } \\
\text { Movimento }\end{array}$ & $\begin{array}{l}243 \text { jogadores de futebol (129 } \\
\text { profissionais e } 103 \text { amadores) do } \\
\text { sexo masculino de diferentes times } \\
\text { do estado do Mato Grosso do Sul, } \\
\text { Brasil }\end{array}$ & $\begin{array}{l}\text { Estudo } \\
\text { descritivo e } \\
\text { observacional, } \\
\text { com desenho } \\
\text { retrospectivo }\end{array}$ & $\begin{array}{l}\text { De acordo com os estudos, a maioria dos jogadores } \\
\text { entrevistados relataram ter tido recidivas das lesões. As lesões } \\
\text { mais comuns nos jogadores de linha são as lesões das } \\
\text { articulações do joelho e no complexo tornozelo/pé, enquanto } \\
\text { que em goleiros são mais comuns lesões das articulações das } \\
\text { mãos e punhos. Em relação a lesões musculares na região } \\
\text { lombar, são mais frequentes em meio-campistas e as lesões } \\
\text { musculares de membros inferiores mais frequentes em } \\
\text { zagueiros, laterais, volantes e atacantes. De todos as posições } \\
\text { em campo, os atacantes apresentaram maiores índices de } \\
\text { lesões. }\end{array}$ & $\begin{array}{l}\text { A posição mais suscetível a lesões foram os } \\
\text { atacantes. As lesões mais frequentes em jogadores } \\
\text { de linha foram as de membros inferiores (joelhos e } \\
\text { tornozelos), ao mesmo tempo que as principais } \\
\text { lesões entre goleiros foram as de punhos e mãos. } \\
\text { Em relação as lesões musculares nos membros } \\
\text { inferiores as posições mais acometidas foram } \\
\text { zagueiros, laterais, volantes e atacantes, enquanto } \\
\text { que as lesões musculares em região lombar foram } \\
\text { mais prevalentes em meio-campistas. }\end{array}$ \\
\hline $\begin{array}{l}\text { Montalvo et al., } \\
\qquad 2018 . \\
\text { British Journal of } \\
\text { Sports Medicine } \\
\text { (BJSM) }\end{array}$ & $\begin{array}{l}162 \text { artigos e } 28 \text { estudos de atletas do } \\
\text { futebol masculino e feminino } \\
\text { (amador, intermediário e elite) que } \\
\text { relataram o total de participantes, } \\
\text { população por sexo, o total de lesões } \\
\text { do LCA por sexo e o tempo total por } \\
\text { pessoa por sexo }\end{array}$ & $\begin{array}{c}\text { Revisão } \\
\text { sistemática com } \\
\text { meta-análise }\end{array}$ & $\begin{array}{l}\text { No total, foram incluídos } 28 \text { estudos para estimar a proporção } \\
\text { de incidência (IP) e a taxa de incidência (IR). Por uma } \\
\text { temporada de } 4 \text { anos o IP e Ir da lesão do ligamento cruzado } \\
\text { anterior em jogadores de futebol do sexo masculino foram de } \\
3,5 \% \text { (IC } 95 \% 0,7 \% \text { a 8,2\%) e } 0,9 / 10.000 \text { AEs (IC } 95 \% 0,7 \text { a } \\
1,1 ; \text { I }^{2}=94 \% \text { ). Não houve diferença de risco relativo entre } \\
\text { jogadores de ambos os sexos durante } 4 \text { anos. }\end{array}$ & $\begin{array}{l}\text { De acordo com os estudos, observa }- \text { se que a } \\
\text { maioria dos que sofreram lesão do LCA foram os } \\
\text { jogadores de futebol do sexo masculino e que o } \\
\text { risco relativo de lesão do LCA é o mesmo para } \\
\text { ambos os sexos durante essa temporada de } 4 \text { anos. }\end{array}$ \\
\hline $\begin{array}{l}\text { Bezuglov et al., } \\
2020 .\end{array}$ & $\begin{array}{l}94 \text { articulações do joelho em } 47 \\
\text { jogadores profissionais de futebol do } \\
\text { sexo masculino (idade média de } 25,7 \\
\pm 4,6 \text { anos, IMC } 22,8 \pm 1,4 \text { ) }\end{array}$ & $\begin{array}{l}\text { Estudo de } \\
\text { coorte } \\
\text { transversal de } \\
\text { nível } 2\end{array}$ & $\begin{array}{l}\text { Todos os atletas do estudo apresentaram ao menos um lesão } \\
\text { condral e meniscal, não houve diferença significante entre } \\
\text { lesões dos membros dominantes e não dominantes, a estrutura } \\
\text { mais afetada foi o corno posterior do menisco medial, os } \\
\text { atletas de maior idade apresentaram mais lesões subcorticais, } \\
\text { lesões patelares e da superfície patelar do fêmur, a maioria dos } \\
\text { atletas tiveram lesões grau II. }\end{array}$ & $\begin{array}{l}\text { Os treinamentos de futebol aumentam a chance dos } \\
\text { atletas terem lesões assintomáticas condrais e } \\
\text { meniscais, idade avançada aumenta o risco de ter } \\
\text { alguns tipos de lesões, a quantidade e a gravidade } \\
\text { das lesões não dependem da dominância das pernas. }\end{array}$ \\
\hline
\end{tabular}




\begin{tabular}{|c|c|c|c|c|}
\hline $\begin{array}{l}\text { Gupta et al., } 2020 . \\
\text { J Clin Orthop } \\
\text { Trauma }\end{array}$ & $\begin{array}{l}\text { Quinhentos e dezessete atletas de } \\
\text { futebol (226) e jogadores Kabaddi } \\
\text { (291) do sexo masculino com idade } \\
\text { entre } 16 \text { e } 35 \text { anos foram incluídos } \\
\text { no estudo. }\end{array}$ & $\begin{array}{l}\text { Estudo } \\
\text { retrospectivo } \\
\text { (coorte), nível } \\
\text { III. }\end{array}$ & $\begin{array}{l}\text { Os atletas de futebol tiveram mais lesões em membros não } \\
\text { dominantes (130) do que dominantes (96), a quantidade de } \\
\text { rupturas nos meniscos medial (133) e lateral (137) foi } \\
\text { semelhante e ruptura dos dois meniscos (94) foi menor em } \\
\text { ambos os esportes, a estrutura mais afetada foi o corno } \\
\text { posterior do menisco, no futebol houve mais danos no côndilo } \\
\text { femoral medial (78) do que no côndilo femoral lateral (17) e } \\
\text { em ambos côndilos (10), atletas com atraso cirúrgico maior } \\
\text { que } 18 \text { meses tinham chance elevada de ter lesões condrais de } \\
\text { alto grau. }\end{array}$ & $\begin{array}{l}\text { Os jogadores de Kabaddi possuíam chance maior } \\
\text { de ter lesões meniscais do que jogadores de futebol } \\
\text { mesmo que com problemas no ligamento cruzado } \\
\text { anterior. Quanto maior o tempo para realizar a } \\
\text { cirurgia após detectada a lesão mais provavelmente } \\
\text { haverá uma gravidade maior. }\end{array}$ \\
\hline $\begin{array}{c}\text { Nitta et al., } 2021 . \\
\text { Medicina } \\
\text { Esportiva }\end{array}$ & $\begin{array}{lcr}\text { Informações } & \text { extraídas } & \text { pela } \\
\text { plataforma } & \text { de } & \text { dados } \\
\text { Transfermrkt.com.br, com } & 5 \\
\text { temporadas } \quad(2015-2019) & \text { dos } \\
\text { campeonatos brasileiros séries A e B } \\
\text { sendo analisadas e revisadas } & \text { por } 3 \\
\text { pesquisadores. }\end{array}$ & $\begin{array}{l}\text { Estudo } \\
\text { Transversal, } \\
\quad \text { estudo } \\
\text { retrospectivo, } \\
\quad \text { nível II }\end{array}$ & $\begin{array}{l}\text { Houveram } 52 \text { lesões no ligamento cruzado anterior no período } \\
\text { do estudo, com os atletas envolvidos tendo uma média de } \\
\text { idade de } 26,3 \text { anos, os atletas de } 1^{\circ} \text { divisão apresentaram mais } \\
\text { lesões do que os de } 2^{\circ} \text { divisão, os atacantes e zagueiros foram } \\
\text { as posições que tiveram maior incidência sem diferença } \\
\text { significativa entre elas. }\end{array}$ & $\begin{array}{l}\text { A incidência das lesões pode variar de acordo com } \\
\text { a posição dos jogadores em campo, sendo os } \\
\text { atacantes e os zagueiros são os grupos mais } \\
\text { propensos a ter lesões do ligamento cruzado } \\
\text { anterior. }\end{array}$ \\
\hline
\end{tabular}

Fonte: Autores. 
Research, Society and Development, v. 10, n. 14, e294101422216, 2021

(CC BY 4.0) | ISSN 2525-3409 | DOI: http://dx.doi.org/10.33448/rsd-v10i14.22216

\section{Discussão}

\subsection{Articulação do Joelho}

O joelho é uma articulação sinovial que se localiza entre o fêmur e a tíbia, assim separando a coxa e a perna, e originando duas articulações, a femurotibial e a femuropatelar. Sua principal estrutura óssea é a patela, que fica na parte anterior do joelho, de formato triangular e ampla no polo proximal, acompanhada pela superfície patelar (com uma porção medial menor e outra lateral maior) (De Castro, 2009).

Essa articulação tem dois tipos de movimentos: flexão-extensão e a rotação em $90^{\circ}$ (Rocha, 2017). Possui cápsula articular (contorna as epífises distal do fêmur e a proximal da tíbia) com uma membrana sinovial no seu interior, responsável pela produção de ácido hialurônico. O líquido sinovial é resultado da filtragem do sangue e a adição de ácido hialurônico (secretado pelos sinoviócitos), atua na lubrificação da articulação (Malta, 2017).

Existe uma cartilagem articular na região, que serve para recobrir as extremidades dos ossos em qualquer tipo de articulação, ajuda na absorção de impactos e facilita a movimentação (De Castro, 2009).

Na porção distal do fêmur existem dois côndilos femorais (medial e lateral), que chegam até a superfície da tíbia, os dois são assimétricos e formam o sulco patelo-femoral que é por onde a patela consegue deslizar. Há também os côndilos tibiais (medial e lateral), cobertos por cartilagem e separados por eminencias intercondilares, eles recebem os meniscos que estão entre o fêmur e a tíbia (De Castro, 2009).

Os meniscos (medial e lateral) são importantes, pois ajudam na estabilidade do joelho, melhora a distribuição de pressões (devido ao aumento da superfície de apoio) e do líquido sinovial, além de ter papel na absorção de choques (Malta, 2017). O menisco medial é maior e tem formato semicircular, bastante largo na parte posterior. O menisco lateral é menor e mais móvel que o medial, com formato semelhante a letra "c" e é largo em quase toda extensão (De Castro, 2009).

Os meniscos se ligam por um pequeno ligamento, chamado de ligamento transverso (De Castro, 2009) e sua vascularização é originada dos vasos geniculares laterais e mediais (superiores e inferiores) (Astur, 2011).

Os ligamentos atuam na estabilidade da região, auxiliados pelos meniscos, evitando que haja movimentos anormais. Também ajudam a absorver impactos e choques. São compostos por tecido conjuntivo fibroso, ou seja, possuem muitas fibras colágenas do tipo I junto com uma pequena quantidade de fibras elásticas (dando uma resistência à tração) (De Castro, 2009).

Os quatros principais ligamentos do joelho são: ligamento cruzado anterior, ligamento cruzado posterior, ligamento colateral medial, ligamento colateral lateral (De Castro, 2009).

Os ligamentos cruzados impedem que o joelho se deforme e ajudam nos movimentos de flexão e rotação, assim gerando uma estabilidade ântero-posterior em extensão (Pinheiro, 2015). O ligamento cruzado anterior (LCA) é originado na eminência intercondilar da tíbia e sobe posteriormente para face interna do côndilo femoral lateral. O ligamento cruzado posterior (LCP) se origina na eminência intercondilar, cruza posteriormente ao LCA e chega à face interna do côndilo femoral medial (Pinheiro, 2015).

Acredita-se que as principais estruturas que propiciam a estabilidade estática extra-articulares são os ligamentos colaterais e a cápsula articular (De Castro, 2009).

O ligamento colateral medial encontra-se fixado ao côndilo femoral medial e a tíbia. Já o ligamento colateral lateral está fixado ao côndilo femoral lateral e a cabeça da fíbula (De Castro, 2009).

O joelho possui vários músculos acessórios, como gastrocnêmio, poplíteo e sartório, além de alguns músculos que atuam de forma direta na articulação, como quadíceps femoral, ísquio-sural, grácil, tensor da fáscia lata (Lemos, 2016). 
O tendão patelar conecta patela a tíbia, se inserir o músculo quadríceps da coxa toda essa estrutura pode ser denominada tendão quadriciptal (Astur, 2011).

Os principais nervos responsáveis pela inervação do joelho são os ciáticos e os femorais. O nervo ciático se divide em ramificações, como nervo tibial e nervo fibular comum. O nervo femoral tem função importante no mecanismo de extensão. As ramificações do nervo ciático estão localizadas na fossa poplítea e inervam a musculatura flexora do joelho. O nervo tibial inerva os músculos semitendinoso, semimembranoso e a cabeça longa do bíceps femoral. Já o nervo fibular comum (ramo do ciático) inerva a cabeça curta do bíceps femoral (De Castro, 2009).

\subsection{Joelho X Futebol}

As estruturas do joelho são bastante requisitadas no futebol e que depois das lesões musculares, elas são as mais frequentes no ambiente futebolístico.

Existem vários tipos de lesões no joelho que são comuns no futebol, como as tendinites, ruptura de meniscos, entorses, luxações e subluxações, fraturas ósseas, ruptura, osteoartrite, estiramentos de tendões (principalmente o patelar) dentre outros (Da Silva, 2018).

O estudo de Bezuglov e colaboradores (2020) comprovou que os treinamentos de futebol aumentam a chance dos atletas terem lesões assintomáticas condrais e meniscais.

Vale lembrar que alguns fatores predispõem para o desenvolvimento de algumas dessas lesões, como o tempo da carreira do jogador, deformidades no joelho como geno varo e valgo, a intensidade do treinamento, dentre outros fatores. É importante lembrar que a maioria das lesões no joelho ocorre ao final das partidas, com baixa frequência durante os treinos e que podem gerar prejuízos tanto para o atleta, quanto para o clube (Oliveira, 2016). A pesquisa realizada por Bezuglov e seus contribuintes (2020) confirma que com avanço da idade o atleta passa a ter risco maior de sofrer lesões e que não há diferença relevante entre as dominâncias das pernas para incidência de lesões.

Nota - se que as lesões ligamentares no joelho são extremamente graves e que demandam uma maior atenção. Dentre os ligamentos do joelho, o mais acometido é o ligamento cruzado anterior que geralmente precisa de intervenção cirúrgica e demanda um tempo maior para o retorno do atleta as partidas de futebol. É comum também que esse tipo de lesão ocorra mutuamente com a lesão do menisco (Da Silva, 2018). Em um estudo feito por Gupta e colaboradores (2020) alegou que foi semelhante a quantidade de rupturas dos meniscos mediais e laterais e que a ruptura dos dois meniscos é menos provável. Além disso, a estrutura mais acometida é o corno posterior do menisco. Outro dado relevante desse mesmo estudo foi que a prevalência de lesões no côndilo femoral medial foi maior que no côndilo femoral lateral e em ambos os côndilos.

Um estudo que analisou dados das últimas temporadas do campeonato brasileiro teve como resultados que as lesões do ligamento cruzado anterior (LCA) são frequentes em jogadores de futebol, tendo uma média de idade em torno de 26 anos. Os atletas da primeira divisão apresentaram mais lesões do que o da segunda divisão, provavelmente pela maior exigência física da competição e as posições mais acometidas foram zagueiros e atacantes devido a grande quantidade de saltos realizados durante a partida (Nitta,2021), conclusão diferente de estudos mais antigos que traziam atacantes e meios de campo como atletas mais acometidos por este tipo de lesão. Já o estudo de Astur (2016) sobre lesões no joelho de diversas modalidades esportivas, concluiu que o tempo de prática para sofrer lesões no LCA é menor do que lesões de outras estruturas do joelho.

O estudo de Waldén e contribuintes (2015) constatou que as principais causas de lesões no LCA são: por pressão, recuperar o equilíbrio após chutar, aterrissar após cabecear e contato direto com perna ou joelho lesionado. Assim jogadores 
Research, Society and Development, v. 10, n. 14, e294101422216, 2021

(CC BY 4.0) | ISSN 2525-3409 | DOI: http://dx.doi.org/10.33448/rsd-v10i14.22216

defensivos estariam mais vulneráveis a sofrerem tais lesões, dessa forma buscar maneiras de melhorar as técnicas que são exigidas durante as partidas é essencial para redução da quantidade de lesões.

Em outro estudo realizado com atletas profissionais de Minas Gerais não houve diferença significativa da ocorrência de lesões em relação à posição dos jogadores, a capacidade de geração de força dos flexores e extensores não depende da posição em campo. Mas observaram que o índice de fadiga dos flexores é maior que os extensores (Carvalhais, 2013).

Existe uma tríade conhecida por O’Donoghue que é composta pelo ligamento colateral medial, ligamento cruzado anterior e menisco medial. De acordo com alguns artigos, a lesão mais grave que pode ocorrer no joelho e quando todos os componentes dessa tríade são afetados ao mesmo tempo. Entretanto, pelo índice de lesões do ligamento cruzado anterior ser alto, ele é o mais temido durante as partidas de futebol (Brito, 2009).

Além disso, esse tipo de lesão acomete mais mulheres, apesar da maioria dos estudos estar voltada para homens por representarem maioria no esporte (Oliveira, 2016). Em contrapartida, um estudo com atletas do futebol masculino e feminino enfatiza que a prevalência é semelhante em ambos os sexos, porém concorda que aparecem mais casos devido a maior quantidade de praticantes no sexo masculino (Montalvo, 2018).

A inflamação do tendão patelar também é bastante comum durante as partidas de futebol e podem acontecer em função de treinos exagerados ou incorretos (Hebert, 2017). A ruptura total do tendão patelar está diretamente relacionada a uma tendinopatia, que pode ser por crônica por hereditariedade ou por traumas que causam danos parciais. A degeneração lenta do tendão é um fator de risco para as lesões mesmo com um alongamento não violento, os idosos estão predispostos porque com a idade o tendão envelhece e as fibras mudam de forma (Defilippo, 2012).

Há vários motivos para ocorrer a lesão patelar, como: deformações ou defeitos anatômicos, joelho valgo ou uma diferença no comprimento das pernas podem forçar o tendão a trabalhar incorretamente, portanto cria uma tendência para a inflamação. Esta lesão acomete frequentemente atletas praticantes de atividades de salto ou aquelas que exigem força de impacto repetitivo com alta intensidade, como o jogador de futebol. A sobrecarga provocar alterações na matriz extracelular, resultando em pequenas lesões que, cronicamente, poderão levar a um quadro de tendinose, principalmente na região do polo inferior da patela (Defilippo, 2012).

Os fatores etiológicos devem ser avaliados no tratamento. A etiologia do tendinopatia patelar é multifatorial, envolvendo causas extrínsecas e intrínsecas (Defilippo, 2012). Extrínsecas: esforço repetitivo com sobrecarga durante atividades de corridas e saltos é um importante fator etiológico para a tendinopatia patelar, sendo comum a incidência em atletas de basquete, vôlei, futebol, atletismo A frequência e a intensidade dos treinos e competições também influenciam no desenvolvimento dos sintomas, assim como maior número de horas de treinamento por semana (Defilippo, 2012). Intrínsecos: O índice de massa corpórea está relacionado com o desenvolvimento da tendinopatia patelar; o maior índice de massa corpórea apresenta maior probabilidade de aparecimento da mesma. Como a altura não está relacionada com tendinopatia patelar, é o maior índice de massa corpórea que apresentará maior predisposição dessa comorbidade (Cohen, 2008).

\subsection{Prevenção e Tratamento}

A melhor forma de prevenção das lesões de joelho é a análise individual de cada atleta, onde deve ser considerada a sua condição muscular (Zabka, 2011) e a forma como executam saltos e aterrissagens, principalmente em jogadores defensivos (Waldén, 2015). Desta forma, os treinos devem ser planejados e específicos para cada atleta, garantindo equilíbrio durante o chute e, consequentemente, redução das possibilidades de lesão (Zabka, 2011; Waldén, 2015). 
Esta afirmação é reforçada por Albanezi (2021). O autor relata que o trabalho de prevenção de lesões deve ser realizado considerando os seguintes aspectos: avaliações realizadas com marcadores bioquímicos, dinamômetro isocinética ou testes funcionais; controle de carga; aquecimento e estratégias de treinamento.

Quanto ao tratamento, a intervenção cirúrgica é uma das mais comuns, principalmente nos casos de lesões ligamentares, sendo a do ligamento cruzado anterior a mais frequente e a que demanda um maior tempo de recuperação do atleta (Barata, 2015). Assim, nesses casos, o procedimento cirúrgico deve ser realizado o quanto antes para evitar o possível agravamento das lesões (Gupta et al, 2020).

\section{Conclusão}

Acredita-se que este estudo poderá levar à reflexão sobre as mais prevalentes lesões de joelho em jogadores de futebol. Observando principalmente as de maior prevalência, nota-se a necessidade constante de novas pesquisas de modo a fornecer informações relevantes que direcionem as ações de prevenção para este agravo. Os resultados mostraram que os zagueiros e atacantes são os grupos mais propensos a se lesionarem pela alta quantidade de saltos realizados durante as partidas, desse modo fica evidente que é necessário procurar técnicas para aperfeiçoamento dos saltos, por exemplo.

Os trabalhos analisados não trazem grandes intervenções para solucionar ou minimizar os principais fatores que acometem os profissionais e amadores do futebol em relação às lesões de joelho. Observa-se que a maioria dos artigos possui abordagem metodológica observacional, o que permite notar o comportamento de um sujeito dentro de um determinado ambiente.

Desta forma, apesar do número expressivo de trabalhos sobre este tema, ainda são necessários outros estudos que melhor identifiquem os fatores envolvidos e descrevam as melhores estratégicas de prevenção para que sejam minimizadas as injúrias em joelhos desses atletas, condição que geralmente reflete em grande impacto negativo sobre suas carreiras. Além disso, novos estudos são fundamentais para avaliar a correlação entre a massa muscular ou os movimentos que realizam no campo de jogo e as lesões de joelho em jogadores de futebol.

\section{Referências}

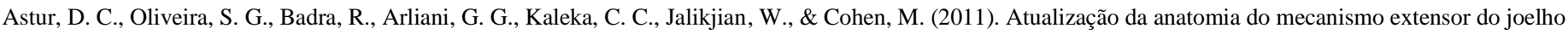
com uso de técnica de visualização tridimensional. Revista Brasileira de Ortopedia, 46, 490-494.

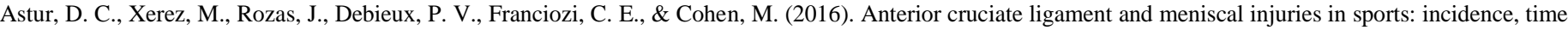
of practice until injury, and limitations caused after trauma th. Revista brasileira de ortopedia, 51, $652-656$.

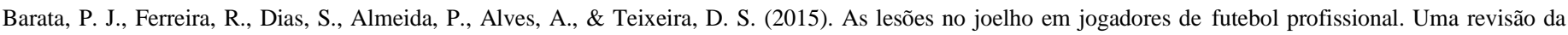
literatura. REDAF: Revista de Desporto e Actividade Física 1, pp. 59-60.

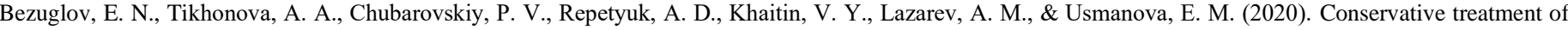
Osgood-Schlatter disease among young professional soccer players. International orthopaedics, 44(9), 1737-1743

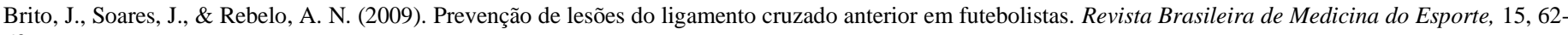
69.

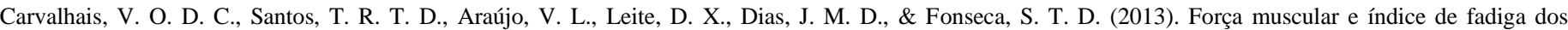

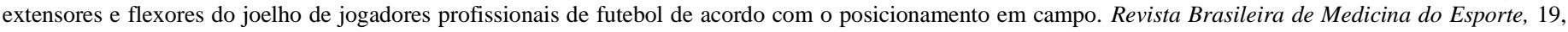
$452-456$.

Cohen, M., Ferretti, M., Marcondes, F. B., Amaro, J. T., \& Ejnisman, B. (2008). Tendinopatia patelar. Revista Brasileira de Ortopedia, 43 , 309-318.

Da Silva, M. C. (2018). Principais Lesões Do Joelho No Futebol Masculino: Uma Revisão Integrativa Da Literatura. FACOL-PE

De Castro, D. M., \& Viera, L. C. R. (2009). Joelho: Revisão de aspectos pertinentes à fisioterapia. 
Research, Society and Development, v. 10, n. 14, e294101422216, 2021

(CC BY 4.0) | ISSN 2525-3409 | DOI: http://dx.doi.org/10.33448/rsd-v10i14.22216

Defilippo, M. (2012). Disponível em: https://www.fisioterapiaparatodos.com/p/anatomia/anatomia-do-joelho/

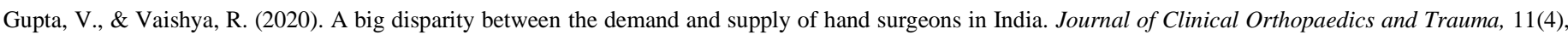
515 .

Lemos, K. D. S., \& Lemos, V. D. S. (2016). O papel da fisioterapia na reabilitação de joelho.

Malta, M. D. S., \& Pacheco, Q. J. F. (2017). Biomecânica do joelho durante o exercício de agachamento dinâmico: revisão narrativa.

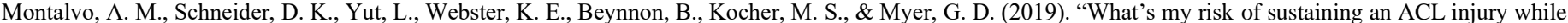
playing sports?" A systematic review with meta-analysis. British journal of sports medicine, 53(16), 1003-1012.

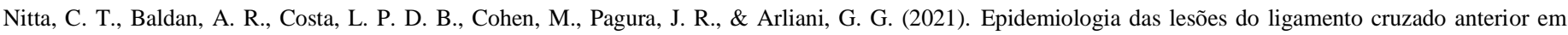
jogadores de futebol do campeonato brasileiro. Acta Ortopédica Brasileira, 29, 45-48.

Oliveira, P. M. C. (2016). Padrões e Incidência de Lesão: estudo de caso na equipa de futebol profissional do Clube Desportivo Feirense.

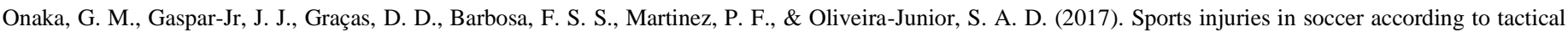
position: a retrospective survey. Fisioterapia em Movimento, 30, 249-257.

Pinheiro, A., \& Sousa, C. V. (2015). Lesão do ligamento cruzado anterior: apresentação clínica, diagnóstico e tratamento. Rev Port Ortop Traum, 23(4), 320-329.

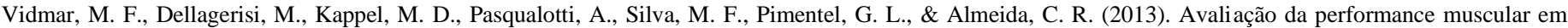
atletas profissionais de futebol de campo. Rev Bras Ciênc Mov, 21(2), 82-8.

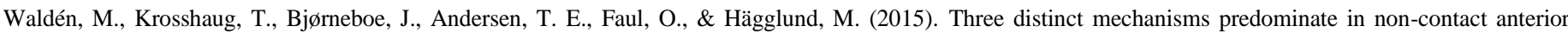
cruciate ligament injuries in male professional football players: a systematic video analysis of 39 cases. British journal of sports medicine, $49(22), 1452-1460$.

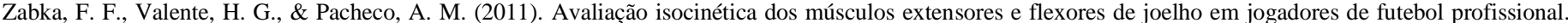
Revista brasileira de medicina do esporte, 17, 189-192. 